\title{
Cholangiocarcinoma: Has there been any progress?
}

\author{
Judith Meza-Junco MD¹, Aldo J Montano-Loza MD², Mang Ma MD², Winnie Wong MD², \\ Michael B Sawyer $M D^{1}$, Vincent G Bain $M D^{2}$
}

J Meza-Junco, AJ Montano-Loza, M Ma, W Wong, MB Sawyer, VG Bain. Cholangiocarcinoma: Has there been any progress? Can J Gastroenterol 2010;24(1):52-57.

Cholangiocarcinoma is the second most common primary hepatic tumour after hepatocellular carcinoma. Primary sclerosing cholangitis is one of the most commonly recognized risk factors for cholangiocarcinoma; however, approximately $90 \%$ of patients have no identifiable risk factors. Extrahepatic type is its most common presentation. Cholangiocarcinoma is considered to be a devastating disease, with a poor survival rate and few therapeutic options. Although surgical resection has been considered the best treatment option for localized cholangiocarcinoma, local recurrences of this cancer are very common, and imply persistent micrometastatic disease in lymph nodes or at surgical margins, even after extended surgical resection. Consequently, the fiveyear survival rate after attempted curative resection is only $20 \%$ to $40 \%$. Early studies of liver transplantation for cholangiocarcinoma did not show a survival benefit and, currently, this tumour is considered to be an absolute contraindication for liver transplantation in most transplant centres worldwide. Recently, neoadjuvant chemoradiation in combination with liver transplantation for highly selected patients with cholangiocarcinoma has shown impressive results, with five-year survival rates at approximately $76 \%$ to $82 \%$ - similar to other standard indications for liver transplantation, such as hepatocellular carcinoma or hepatitis C-induced cirrhosis. However, this success of liver transplantation applies to only a subset of patients and most of the data originated from a single centre. Wider application of this strategy, especially for patients with potentially resectable disease, will require validation by other centres.

Key Words: Cholangiocarcinoma; Liver transplant; Neoadjuvant chemoradiation; Primary sclerosing cholangitis

\section{Le cholangiocarcinome : Y a-t-il des progrès ?}

Le cholangiocarcinome est la deuxième tumeur hépatique primaire en importance après le carcinome hépatocellulaire. La cholangite sclérosante primaire en est l'un des principaux facteurs de risque, mais environ $90 \%$ des patients ne présentent aucun facteur de risque identifiable. La présentation extrahépatique est la plus courante. Le cholangiocarcinome est considéré comme une maladie dévastatrice, au faible taux de survie et aux possibilités thérapeutiques rares. Même si la résection chirurgicale est perçue comme la meilleure possibilité thérapeutique de cholangiocarcinome localisé, les récurrences locales de ce cancer sont très fréquentes et comprennent une maladie micrométastatique persistante dans les ganglions lymphatiques ou les marges chirurgicales, même après une résection chirurgicale élargie. Par conséquent, le taux de survie au bout de cinq ans après une tentative de résection chirurgicale est de l'ordre de seulement $20 \%$ à $40 \%$. Les études précoces de greffe du foie pour traiter le cholangiocarcinome n'ont pas révélé de bienfaits sur la survie et, pour l'instant, cette tumeur est considérée comme une contre-indication absolue à la greffe du foie dans la plupart des centres de transplantation de par le monde. Récemment, une chimioradiation adjuvante associée à une greffe du foie chez des patients atteints d'un cholangiocarcinome hautement sélectionnés a donné des résultats impressionnants, la survie au bout de cinq ans s'élevant à environ $76 \%$ à $82 \%$, un taux similaire aux autres indications standards de greffe du foie, telles que le carcinome hépatocellulaire ou la cirrhose induite par l'hépatite C. Cependant, la réussite de la greffe du foie s'applique seulement à un sous-groupe de patients, et la plupart des données proviennent d'un seul centre. Il faudra valider dans d'autres centres si cette stratégie, notamment chez les patients atteints d'une maladie au potentiel de résection, peut être appliquée à plus grande échelle.

\begin{tabular}{|c|c|}
\hline $\begin{array}{l}\text { Cholangiocarcinoma (CCA) is a neoplasm that originates } \\
\text { from the bile duct epithelium. It accounts for only } 3 \% \text { of } \\
\text { gastrointestinal tumours and is the second most common pri- } \\
\text { mary hepatic tumour after hepatocellular carcinoma (1). The } \\
\text { incidence and mortality of CCA in North America and Europe } \\
\text { has increased dramatically in the past decades }(2,3) \text {. In Canada } \\
\text { and the United States respectively, there are approximately } \\
400 \text { and } 5000 \text { new cases diagnosed each year }(4) \text {. Extrahepatic } \\
\text { type CCAs, including cancers involving the confluence of the } \\
\text { right and left hepatic ducts are the most common ( } 80 \% \text { to } \\
90 \% \text { ); intrahepatic CCAs account for only } 5 \% \text { to } 10 \% \text { of all } \\
\text { CCAs (1). } \\
\text { RISK FACTORS FOR CCA } \\
\text { Primary sclerosing cholangitis (PSC) is the major risk factor for } \\
\text { CCA in the western world. The lifetime risk of CCA has been }\end{array}$ & $\begin{array}{l}\text { reported to be between } 5 \% \text { and } 15 \% \text {, with an annual incidence } \\
\text { rate of } 0.6 \% \text { to } 1.5 \% \text {. CCA is usually diagnosed within the first } \\
\text { two to three years after the diagnosis of PSC has been estab- } \\
\text { lished ( } 5-7) \text {. Other identified risk factors for CCA develop- } \\
\text { ment include secondary sclerosing cholangitis due to recurrent } \\
\text { pyogenic cholangitis and liver fluke infestation, choledochal } \\
\text { cysts and exposure to the x-ray contrast medium thorotrast; } \\
\text { however, most cases of CCA (approximately 90\%) appear to } \\
\text { occur sporadically in patients without obvious risk factors (8). } \\
\text { Unfortunately, both intra- and extrahepatic CCAs are most } \\
\text { commonly diagnosed at advanced stages because of an absence } \\
\text { of specific symptoms, physical examination findings or labora- } \\
\text { tory abnormalities in early or premalignant stages (9). Currently, } \\
\text { diagnostic modalities for CCA include serum tumour markers, } \\
\text { radiological and endoscopic imaging, and pathological analysis } \\
\text { of biopsies or endoscopic brushings. }\end{array}$ \\
\hline
\end{tabular}

${ }^{1}$ Department of Medical Oncology, Cross Cancer Institute, ${ }^{2}$ Division of Gastroenterology $\mathcal{G}$ Liver Unit, Zeidler Ledcor Centre, University of Alberta, Edmonton, Alberta

Correspondence: Dr Judith Meza-Junco, Department of Oncology, Cross Cancer Institute, 11560 University Avenue, Edmonton, Alberta

T6G 122. Telephone 780-577-8125, fax 780-432-8888, e-mail judimeza@cancerboard.ab.ca

Received for publication July 28, 2008. Accepted February 8, 2009 
TABLE 1

Imaging methods for diagnosis of cholangiocarcinoma

\begin{tabular}{|c|c|c|c|}
\hline Imaging method & Author (reference) & Indication & Diagnostic accuracy, \% \\
\hline \multirow[t]{3}{*}{ Computed tomography } & Slattery and Sahani (15) & Assessing resectability & $60-75$ \\
\hline & Kim et al (18) & Detect distant metastases & 79 \\
\hline & & Detect regional node metastases & $50-61$ \\
\hline \multirow{3}{*}{$\begin{array}{l}\text { Magnetic resonance imaging/magnetic resonance } \\
\text { cholangiopancreatography }\end{array}$} & Slattery and Sahani (15) & Detect bile duct involvement & 84 \\
\hline & Manfredi et al (16) & Detect portal encasement & 67 \\
\hline & & Detect liver invasion & 75 \\
\hline \multirow[t]{2}{*}{ Endoscopic retrograde cholangiopancreatography } & Brugge (17) & Primary tumour detection & $70-80$ \\
\hline & & Combined with intraductal ultrasound & $88-90$ \\
\hline \multirow[t]{4}{*}{ Positron emission tomography and computed tomography } & Slattery and Sahani (15) & Primary tumour detection & 83 \\
\hline & Kim et al (18) & Detect regional lymph node metastases & $76-86$ \\
\hline & & Detect distant metastases & 88 \\
\hline & & Change management decision & $16-30$ \\
\hline
\end{tabular}

\section{DIAGNOSIS OF CCA}

Serum carbohydrate antigen (CA) 19-9 is the most commonly used tumour marker for CCA, and in patients with PSC has a sensitivity of $78.6 \%$ and a specificity of $98.5 \%$ using a cut-off value of greater than $129 \mathrm{U} / \mathrm{mL}$; an increase equal to or greater than $67.3 \mathrm{U} / \mathrm{mL}$ over time provided a sensitivity of $90 \%$ and specificity of $98 \%$ for CCA alone. However, in patients with unexplained biliary obstruction without PSC, the sensitivity of CA 19-9 for detecting malignancy has been reported to be $53 \%$ (cut-off value greater than $100 \mathrm{U} / \mathrm{mL}$ ), whereas true negative rates for patients with nonmalignant liver disease or benign biliary strictures is $76 \%$ and $92 \%$, respectively $(10,11)$. Combining tumour markers, such as carcinoembryonic antigen (CEA) and CA 19-9 using the formula: CA $19-9+($ CEA $\times 40)$, with a cutoff value of $400 \mathrm{U}$, gave an accuracy of $86 \%$ for the diagnosis of CCA in PSC patients (12). It is important to note that CA 19-9 levels depend on the Lewis phenotype (blood group type). Considering that approximately $7 \%$ of the population is Lewis-negative, CA 19-9 levels would, consequently, be undetectable (13).

Currently, magnetic resonance cholangiopancreatography is the most useful imaging method to evaluate CCA, providing information about regional tumour extension, biliary anatomy and intrahepatic metastases (14-17). Recent data showed the usefulness of integrated positron emission tomography and computed tomography over conventional imaging (computed tomography, magnetic resonance imaging and magnetic resonance cholangiopancreatography) in patients with suspected and potentially operable CCA, demonstrating a significantly higher accuracy for diagnosis of regional lymph node metastases and distant metastases. Moreover, integrated positron emission tomography and computed tomography has an important clinical impact on selection of proper treatment because it changed management in $15 \%$ to $25 \%$ of patients $(18,19)$ (Table 1 ).

Brush cytology or bile duct biopsies at endoscopic retrograde cholangiopancreatography are the most useful tools to obtain a histological diagnosis of CCA. Sensitivity for conventional brush cytology varies from $37 \%$ to $63 \%$, with specificity ranging from $89 \%$ to $100 \%(20-24)$.

Digital image analysis (DIA) and fluorescence in situ hybridization (FISH) are new, advanced cytological techniques that have emerged to improve the diagnostic accuracy for CCA and are based on the identification of aneuploidy. DIA is a technique that uses a microscope and camera to quantify the amount of cellular DNA, chromatin distribution and nuclear morphology that are suggestive of malignancy. FISH uses fluorescencelabelled DNA probes to detect chromosomal abnormalities in cells and has been shown to detect malignancy in cytological specimens (25-28) (Table 2).

All of the above diagnostic modalities are complimentary and should be used to diagnose and stage CCA accurately. Without accurate diagnosis and staging, it would be difficult to select the appropriate treatment and study the natural history of disease recurrence after surgical resection or liver transplantation (LT).

\section{CCA staging}

CCA is usually staged according to the Tumour/Node/ Metastasis classification by the American Joint Committee on Cancer, which includes stages I to IV (29). Regarding anatomical location, CCA is classified as intrahepatic and extrahepatic. Extrahepatic CCA can further be subdivided into types I to IV, according to the Bismuth classification (1).

\section{Biological characteristics of CCA}

To improve the diagnosis and management of CCA, the particular biological features of this cancer should be considered. As recently summarized by Gores et al (30), hepatic resection is frequently impossible, especially because the most common location is perihilar, commonly surrounding but rarely invading the portal vein and hepatic artery. Extension directly into the liver or along the biliary tree is frequent. The affinity of CCA for bile results in radial spread, but usually does not cause a mass lesion that is discernible on imaging studies. Furthermore, CCA has desmoplastic features that make it difficult to obtain high-quality cells for biliary cytology. Finally, CCA mainly recurs regionally, consistent with the notion of micrometastatic disease at resection margins or in lymph nodes. Five-year survival rates following surgical resection with curative intent ranged from $20 \%$ to $40 \%$ due to CCA recurrence (30).

Therefore, the development of new approaches to achieve more effective control of regional disease in combination with surgical removal should result in improved clinical outcomes.

\section{CCA TREATMENT}

CCA treatment is challenging, particularly due to the propensity of this tumour to disseminate at the time of diagnosis. 
TABLE 2

Tumour markers and cytological methods for diagnosis of cholangiocarcinoma

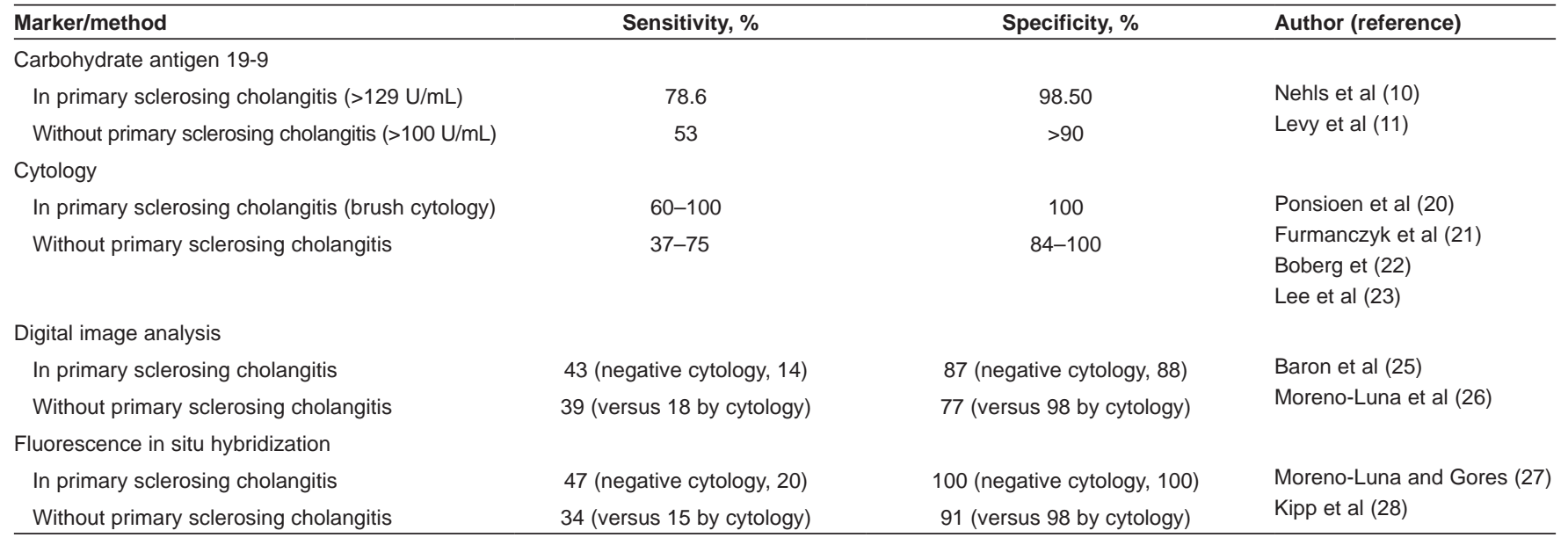

TABLE 3

Outcomes of cholangiocarcinoma patients undergoing surgical resection

\begin{tabular}{lccc}
\hline Author (reference) & $\mathbf{n}$ & $\begin{array}{c}\text { Five-year } \\
\text { survival rate, \% }\end{array}$ & Recurrence, \% \\
\hline De Oliveira et al (36) & 564 & 18 & NR \\
Pichlmayr et al (38) & 125 & 27 & NR \\
Pichlmayr et al (47) & 32 & 20 & NR \\
Casavilla et al (48) & 34 & 31 & 62 \\
Iwatsuki et al (46) $^{\dagger}$ & 34 & 9 & 55 \\
Rea et al (53) & 26 & 21 & 27 \\
\hline
\end{tabular}

*Survival for patients with margin-free resection of intrahepatic cholangiocarcinoma was 63\%; ' Sixty per cent of patients received external radiotherapy with or without 5-fluorouracil sensitization before or after the operation. NR Not reported

Therefore, it is considered to be a devastating cancer, usually with an ominous prognosis. In 1974, Launois et al $(31,32)$ were the first to propose radical surgical resection as a potentially curative option for CCA, suggesting an improvement of survival. Patient survival after surgery is directly related to the ability to attain negative resection margins and the absence of spread to regional lymph nodes. Resectability rates may be as high as $65 \%$; however, curative resection or margin-free resection rates are usually less than 50\% (33). Moreover, surgical resection has been associated with five-year survival rates of $9 \%$ to $63 \%$ (34-36). Overall five-year survival rates have been reported to be $30 \%$ to $41 \%$ for hilar tumours, $31 \%$ to $63 \%$ for intrahepatic tumours and $27 \%$ to $37 \%$ for extrahepatic CCA when margin-free resection is achieved (37-39) (Table 3). This neoplasm mainly recurs regionally, which implies persistent micrometastatic nodal disease or disease at resection margins despite extended surgical resection. This regional recurrence is frequent and devastating. Mortality rates of surgical resection are $5 \%$ to $10 \%$, with most deaths resulting from infection. The perioperative morbidity rates vary between $31 \%$ and $85 \%$ (40).

Otherwise, there are no standard treatments for metastatic CCA. Several small studies of single-agent or combined chemotherapy regimens for unresectable CCA using drugs such as 5-fluorouracil (5-FU) (administered by bolus or infusion), capecitabine, cisplatin, mitomycin C, paclitaxel, oxaliplatin and gemcitabine have been reported. In general, these trials have demonstrated little efficacy, with partial response rates ranging from $0 \%$ to $30 \%$ and median survivals of between two and 12 months (41). Gemcitabine alone or in combination with 5-FU or capecitabine may be a reasonable option for patients not considered candidates for surgery but able to tolerate chemotherapy, although this conclusion has not been confirmed in a randomized controlled trial (42).

\section{Incidental CCA in LT}

Incidental CCA in patients who underwent LT have shown poor results. In a multicentre study from Canada, Ghali et al (43) reported outcomes after LT in 10 recipients found to have incidental CCA in their explanted native liver. The median duration of follow-up was 28 months, eight of 10 patients had PSC, and all tumours were stage I or II (no invasion beyond the bile duct and negative lymph nodes). The three-year survival rate was 30\%, with a median time to recurrence of 26 months and a median time to death of 30 months. These results showed that intermediate- and long-term survival rates were no better than those for individuals transplanted with an established diagnosis of CCA and emphasizes the importance of screening PSC patients for CCA before LT.

Goss et al (44) reported their experience with 127 PSC patients who underwent LT. A total of 113 patients (89\%) were transplanted without evidence of CCA, and had one-, two- and five-year survival rates of $90 \%, 88 \%$ and $87 \%$, respectively. On the other hand, four patients (3\%) with known CCA at the time of LT had tumour recurrence within six months of follow-up. The one-, two- and five-year survival rates were $33 \%, 32 \%$ and $0 \%$, respectively, and were significantly worse than in patients without known CCA.

Other studies have reported somewhat better survival rates for patients with incidental CCA after LT. Becker et al (45) evaluated a multi-institutional experience of LT for CCA in 280 patients who were identified from the United Network for Organ Sharing database. Patients were stratified into three groups: CCA patients transplanted before $1994(\mathrm{n}=101)$, CCA patients transplanted after $1994(\mathrm{n}=102)$ and incidental CCA patients $(n=77)$. Interestingly, patients with an incidental diagnosis of CCA at the time of LT had five-year survival rates that 
were similar to those transplanted for CCA before 1994 (20\% versus 30\%, respectively), and poorer survival rates than patients with CCA transplanted after 1994 (20\% versus 63\%, respectively; $\mathrm{P}<0.01$ ).

A group at the University of Pittsburgh (Pittsburgh, Pennsylvania, USA) showed slightly better results in a cohort of 27 patients who underwent LT, with a five-year survival rate of $36 \%$. The six surviving patients had T1 or T2 tumours, and four had received preoperative radiotherapy (46).

Taken together, all of these results imply that LT in patients with incidental CCA confers poor outcomes, because overall survival rates at five years vary from $0 \%$ to $36 \%$; therefore, it is important to rule out this malignancy, particularly in patients at high risk (ie, PSC) waiting for LT. It may be helpful to try external beam irradiation in these incidental CCA cases in an attempt to neutralize what is believed to be nodal micrometastatic disease; however, this therapeutic strategy has not been evaluated in clinical trials.

\section{LT for CCA}

There is a subgroup of patients with CCA in whom surgical resection is not possible even when there are no known metastases. These patients have bilateral involvement of hepatic ducts or underlying cirrhosis. For these patients, LT appears to be a potential treatment.

Early reports of LT for CCA demonstrated five-year survival rates of $0 \%$ to $20 \%$; these series included patients with metastatic nodes, bilobar CCA, and multiple or large-size solitary CCA $(38,47)$. In addition, other authors reported five-year survival rates of $23 \%$ to $26 \%$, and recurrence rates of $51 \%$ to $84 \%$ after LT for unresectable extrahepatic CCA (48-50). Liver transplant centres in Spain reported similar results, with a three-year survival rate of $30 \%$ (51).

Unfortunately, due to historical data that have shown unacceptable results for CCA, this therapeutic option is discouraged and most transplant centres worldwide have considered CCA an absolute contraindication for LT.

\section{Neoadjuvant chemoradiation for CCA}

In recent years, a few centres have applied rigorous selection criteria and pretransplant neoadjuvant chemoradiation in CCA patients. The results were significantly better and have renewed debate over LT feasibility for CCA. Because the combination of neoadjuvant chemoradiation and LT has achieved promising results, this new approach has been proposed to attempt to control tumour growth during the potentially long wait time for LT and decrease recurrence after LT.

In 2002, a group (Sudan et al [52]) from the University of Nebraska (Lincoln, Nebraska, USA) evaluated the effects of neoadjuvant chemoradiation combined with LT in a selected group of patients with hilar CCA. The neoadjuvant protocol included 6000 cGy biliary brachytherapy and intravenous infusion of 5-FU $\left(300 \mathrm{mg} / \mathrm{m}^{2} /\right.$ day) until transplantation. Five of 17 patients progressed before LT, and one died because of sepsis. Of 11 patients who underwent LT, five (45\%) were alive and without evidence of tumour recurrence during a median follow-up of eight years. The results of LT for CCA are summarized in Table 4. These widely disparate results showed that the patient groups were heterogeneous and the effectiveness of neoadjuvant treatment varied. It also emphasizes the importance of accurate tumour staging.

\section{TABLE 4}

Outcomes of cholangiocarcinoma patients treated with liver transplantation

\begin{tabular}{llll}
\hline Author (reference) & n & Five-year survival rate & Recurrence, \% \\
\hline
\end{tabular}

Liver transplantation not including neoadjuvant chemoradiation

$\begin{array}{lrcc}\text { Pichlmayr et al (38) } & 25 & 17 \% & \text { NR } \\ \text { Pichlmayr et al (47) } & 18 & 14 \% \text { at 1 year } & \text { NR } \\ \text { Casavilla et al (48) } & 20 & 18 \% & 55 \\ \text { Shimoda et al (49) } & 25 & 35 \% \text { at 3 years } & 41 \\ \text { Robles et al (51)* } & 59 & 30 \% \text { and } 42 \% & 53 \text { and } 35 \\ & & 18 \% \text { and 23\% at 10 years } & \\ \text { Becker et al (45) } & 102 & 63 \% & \text { NR } \\ & 101 & 30 \% & \text { NR }\end{array}$

Liver transplantation including incidental cholangiocarcinoma

$\begin{array}{llcc}\text { Ghali et al (43) } & 10 & 30 \% \text { at 3 years } & 80 \\ \text { Goss et al (44) } & 10 & 83 \% & \text { NR } \\ \text { Becker et al (45) } & 77 & 20 \% & \text { NR }\end{array}$

Neoadjuvant chemoradiation and liver transplantation for cholangiocarcinoma

$\begin{array}{llcl}\text { Iwatsuki et al (46) } & 27 & 25 \% & 55 \\ \text { Sudan et al (52) } & 11 & 45 \% \text { at 7 years } & 18 \\ \text { Rea et al (53) } & 38 & 82 \% & 13 \\ \text { Heimbach et al (56) } & 65 & 76 \% & 17\end{array}$

${ }^{*}$ Results are presented for hilar $(n=36)$ and peripheral $(n=23)$ cholangiocarcinoma respectively. ${ }^{\dagger}$ Patients transplanted before 1994 ( $\left.n=101\right)$, and patients transplanted after 1994 ( $n=102)$. ${ }^{\ddagger}$ Sixty per cent of patients received external radiotherapy with or without 5-fluorouracil sensitization before or after liver transplantation. Six of eight patients who survived more than five years received radiotherapy (four preoperatively and two postoperatively). NR Not reported

\section{MAYO CLINIC PROTOCOL OF LT FOR CCA}

By applying strategies of more rigorous selection criteria and intensive neoadjuvant chemoradiotherapy regimens, the Mayo Clinic (Rochester, Minnesota, USA) has been able to obtain significantly improved outcomes after LT in unresectable extrahepatic CCA. Of 71 patients who were enrolled in the treatment protocol, 54 were evaluated for surgical resection and 38 underwent LT. Patients treated with LT received neoadjuvant therapy, including external beam radiotherapy, with a target dose of $4500 \mathrm{cGy}$ in 30 fractions and a transluminal boost of radiation using a transcatheter iridium-192 brachytherapy wire, with a target dose of 2000 cGy to 3000 cGy. Concomitantly, 5-FU was administered at $500 \mathrm{mg} / \mathrm{m}^{2}$ as a daily intravenous bolus for the first three days of radiation. Patients continued to receive oral capecitabine $\left(2000 \mathrm{mg} / \mathrm{m}^{2} /\right.$ day in two divided doses, two out of every three weeks) as tolerated until LT. All patients underwent a staging operation before transplantation; extrahepatic metastases, lymphatic node metastases, and local extension of disease to adjacent organs or tissues precluded LT. Thus, only patients with operatively confirmed stage I to II disease underwent LT.

Of 54 patients in the surgical group, 26 (48\%) underwent surgical resection, and 28 (52\%) had unresectable disease. One-, three- and five-year patient survival rates were $82 \%$, $48 \%$ and $21 \%$, respectively, after surgical resection, and $92 \%$, $82 \%$ and $81 \%$, respectively after LT $(\mathrm{P}<0.02)$. There were fewer tumour recurrences in transplanted patients than in surgical patients (13\% versus 27\%). Eight patients in the LT group did not have tissue or cytology diagnoses of CCA in 
the explanted livers; however, they had suspicious cytology, malignant-appearing strictures, high CA 19-9 levels without acute biliary obstruction, and positive DIA and FISH tests for aneuploidy at the time of evaluation for LT. Moreover, when excluding these eight patients from the survival analysis, the five-year survival rate only changed from $82 \%$ to $80 \%$ (53). An update of this protocol was presented at the Third Annual Canadian Liver Transplant Forum in November 2007. Up to October 2007, 148 patients, of which 124 underwent a staging operation, have been included, with 90 undergoing LT. The mean $( \pm \mathrm{SD})$ five-year survival rate after the start of therapy in 148 patients was $55 \pm 6 \%$ and five-year survival after LT in the 90 patients was $71 \pm 7 \%$ (personal communication).

\section{LT for intrahepatic CCA}

Contrary to the favourable outcomes with LT for extrahepatic perihilar CCA reported by a single centre (Mayo Clinic), intrahepatic CCA treated with LT confers high rates of disease recurrence and poor survival and, thus, cannot be advocated. Median survival of these patients has been reported to be just five months. Overall survival at one year ranges from $14 \%$ to $70 \%$, from $34 \%$ to $50 \%$ at three years, and from $0 \%$ to $33 \%$ at five years in series with few patients with intrahepatic CCA treated with LT $(54,55)$.

\section{Predictors of disease recurrence after LT}

The same group has also reported their experience regarding clinicopathological predictors for disease recurrence (56). Up to January 2006, 106 patients had been enrolled in this protocol. Eleven patients had died or had evidence of disease spread before neoadjuvant treatment was completed, and 18 patients experienced disease progression diagnosed at laparotomy and were therefore, excluded from the study. Of the remaining 87 patients, 65 transplants have been reported to date. For these 65 patients, one- and five-year survival rates were $91 \%$ and $76 \%$, respectively; 11 patients (17\%) developed recurrence between seven and 64 months after LT (median 22 months); and eight patients died from recurrent disease within a median follow-up of 18 months. The predictors of recurrence were older age, pretransplant CA 19-9 level greater than $100 \mathrm{U} / \mathrm{mL}$, previous cholecystectomy, mass detected on cross-sectional imaging, residual tumour in explant greater than $2 \mathrm{~cm}$ in size, tumour grade and perineural invasion in explant. PSC, percutaneous biliary intubation and sex were not associated with recurrence.

\section{Should LT for CCA be performed in other centres?}

It may be difficult to generalize the Mayo Clinic protocol to all transplant centres. Given the chronic organ shortage, it is important that the favourable results reported by the Mayo Clinic be reproduced if the protocol is to be applied more widely. This is a complex protocol for highly selected patients, in which patients are declined participation if they do not fulfill rigorous criteria. A dedicated team of oncologists, hepatologists, radiotherapists, endoscopists and transplant surgeons will be needed to manage these patients. Only centres with such a multidisciplinary team may wish to incorporate this protocol into their transplant indications and attempt to gain experience to achieve similar or better results. Further refinements to the protocol may be possible. Currently, the protocol is a 'package deal', but are each of the different components critical to its success? What is the relative importance of debulking the primary tumour versus treatment of microscopic tumour deposits in regional lymph nodes?

It will be important to clarify which CCA patients should undergo LT. It appears that PSC patients with localized extrahepatic CCA may benefit from LT because surgical resection in this setting is a temporizing measure at best and may complicate future LT. However, surgical resection outcomes are improving with the recognition that the caudate lobe requires removal in hilar cancers and vascular reconstruction can be performed safely (57). In these cases, surgical resection avoids the laborious process of chemoradiation and the necessity of lifelong post-transplant immunosuppression.

For patients with unresectable extrahepatic CCA meeting the Mayo Clinic criteria for LT, this approach offers the only chance for cure.

\section{SUMMARY}

CCA is a devastating disease with a poor survival rate and few therapeutic options. Although surgical resection has been considered to be the best treatment option for localized CCA, local recurrences are very common, which implies persistent micrometastatic disease in the regional lymph nodes or at surgical margins. Early studies of LT for CCA did not show a survival benefit and currently, this tumour is considered to be an absolute contraindication for LT in most transplant centres worldwide. Recently, neoadjuvant chemoradiation in combination with LT for highly selected patients with extrahepatic CCA has shown impressive results, albeit at a single centre, five-year survival is approximately $76 \%$ to $82 \%$, thereby approximating results for other standard indications for LT. It qualifies as an important advance in the battle to cure hilar CCA. Wider application of this strategy for CCA treatment, especially for patients with potentially resectable disease, will require validation by other centres.

\section{REFERENCES}

1. Blechacz BR, Gores GJ. Cholangiocarcinoma. Clin Liver Dis 2008; $12: 131-50$.

2. Patel T. Increasing incidence and mortality of primary intrahepatic cholangiocarcinoma in the United States. Hepatology 2001;33:1353-7.

3. Shaib YH, Davila JA, McGlynn K, El-Serag HB. Rising incidence of intrahepatic cholangiocarcinoma in the United States: A true increase? J Hepatol 2004;40:472-7.

4. Shaib Y, El-Serag HB. The epidemiology of cholangiocarcinoma. Semin Liver Dis 2004;24:115-25.

5. Broome U, Olsson R, Loof L, et al. Natural history and prognostic factors in 305 Swedish patients with primary sclerosing cholangitis. Gut 1996;38:610-5.

6. Burak K, Angulo P, Pasha TM, Egan K, Petz J, Lindor KD. Incidence and risk factors for cholangiocarcinoma in primary sclerosing cholangitis. Am J Gastroenterol 2004;99:523-6.

7. Bergquist A, Ekbom A, Olsson R. Hepatic and extrahepatic malignancies in primary sclerosing cholangitis. J Hepatol 2002;36:321-7.

8. Patel T. Cholangiocarcinoma. Nat Clin Pract Gastroenterol Hepatol 2006;3:33-42.

9. Yachimski P, Pratt DS. Cholangiocarcinoma: Natural history, treatment, and strategies for surveillance in high-risk patients. J Clin Gastroenterol 2008;42:178-90.

10. Nehls O, Gregor M, Klump B. Serum and bile markers for cholangiocarcinoma. Semin Liver Dis 2004;24:139-54.

11. Levy C, Lymp J, Angulo P, Gores GJ, Larusso N, Lindor KD. The value of serum CA 19-9 in predicting cholangiocarcinomas in patients with primary sclerosing cholangitis. Dig Dis Sci 2005;50:1734-40. 
12. Ramage JK, Donaghy A, Farrant JM, Iorns R, Williams R. Serum tumor markers for the diagnosis of cholangiocarcinoma in primary sclerosing cholangitis. Gastroenterology 1995;108:865-9.

13. Steinberg W. The clinical utility of the CA 19-9 tumor associated antigen. Am J Gastroenterol 1990;85:350-5.

14. Khan SA, Davidson BR, Goldin R, et al. Guidelines for the diagnosis and treatment of cholangiocarcinoma: Consensus document. Gut 2002;51(Suppl 6):1-9.

15. Slattery JM, Sahani DV. What is the current state-of-the-art imaging for detection and staging of cholangiocarcinoma? Oncologist 2006;11:913-22.

16. Manfredi R, Barbaro B, Masselli G, Vecchioli A, Marano P. Magnetic resonance imaging of cholangiocarcinoma. Semin Liver Dis 2004:24:155-64.

17. Brugge WR. Endoscopic techniques to diagnose and manage biliary tumors. J Clin Oncol 2005;23:4561-5.

18. Kim JY, Kim MH, Lee TY, et al. Clinical role of (18) F-FDG PET-CT in suspected and potentially operable cholangiocarcinoma: A prospective study compared with conventional imaging. Am J Gastroenterol 2008;102:1-7.

19. Corvera CU, Blumgart LH, Akhurst T, et al. ${ }^{18} \mathrm{~F}$-fluorodeoxyglucose positron emission tomography influences management decisions in patients with biliary cancer. J Am Coll Surg 2008;206:57-65.

20. Ponsioen CY, Vrouenraets SM, van Milligen de Wit AW, et al. Value of brush cytology for dominant strictures in primary sclerosing cholangitis. Endoscopy 1999;31:305-9.

21. Furmanczyk PS, Grieco VS, Agoff SN. Biliary brush cytology and the detection of cholangiocarcinoma in primary sclerosing cholangitis: Evaluation of specific cytomorphologic features and CA 19-9 levels. Am J Clin Pathol 2005;124:355-60.

22. Boberg KM, Jebsen P, Clausen OP, Foss A, Aabakken L, Schrumpf E. Diagnostic benefit of biliary brush cytology in cholangiocarcinoma in primary sclerosing cholangitis. J Hepatol 2006;45:568-74.

23. Lee JG, Leung JW, Baillie J, Layfield LJ, Cotton PB. Benign, dysplastic, or malignant - making sense of endoscopic bile duct brush cytology: Results in 149 consecutive patients. Am J Gastroenterol 1995;90:722-6.

24. Xing GS, Geng JC, Han XW, Dai JH, Wu CY. Endobiliary brush cytology during percutaneous transhepatic cholangiodrainage in patients with obstructive jaundice. Hepatobiliary Pancreat Dis Int 2005;4:98-103

25. Baron TH, Harewood GC, Rumalla A, et al. A prospective comparison of digital image analysis and routine cytology for the identification of malignancy in biliary tract strictures. Clin Gastroenterol Hepatol 2004;2:214-9.

26. Moreno-Luna LE, Kipp B, Halling KC, et al. Advanced cytologic techniques for the detection of malignant pancreatobiliary strictures. Gastroenterology 2006;131:1064-72.

27. Moreno-Luna LE, Gores GJ. Advances in the diagnosis of cholangiocarcinoma in patients with primary sclerosing cholangitis. Liver Transpl 2006;12:S15-9.

28. Kipp BR, Stadheim LM, Halling SA, et al. A comparison of routine cytology and fluorescence in situ hybridization for the detection of malignant bile duct strictures. Am J Gastroenterol 2004;99:1675-81.

29. Fleming ID, Cooper JS, Hensen DE, et al. AJCC (American Joint Committee on Cancer) cancer staging manual, 5th edn. Philadelphia: Lippincott-Raven, 1998.

30. Gores GJ, Nagorney DM, Rosen CB. Cholangiocarcinoma: Is transplantation an option? For whom? J Hepatol 2007;47:455-9.

31. Launois B, Campion JP, Brissot P, Gosselin M. Carcinoma of the hepatic hilus. Surgical management and the case for resection. Ann Surg 1979;190:151-7.

32. Launois B, Terblanche J, Lakehal M, et al. Proximal bile duct cancer: High resectability rate and 5-year survival. Ann Surg 1999;230:266-75

33. Nagorney DM, Kendrick ML. Hepatic resection in the treatment of hilar cholangiocarcinoma. Adv Surg 2006;40:159-71.

34. Yeh CN, Jan YY, Yeh TS, Hwang TL, Chen MF. Hepatic resection of the intraductal papillary type of peripheral cholangiocarcinoma. Ann Surg Oncol 2004;11:606-11.

35. Ohtsuka M, Ito H, Kimura F. Results of surgical treatment for intrahepatic cholangiocarcinoma and clinicopathological factors influencing survival. Br J Surg 2002;89:1525-31.

36. De Oliveira ML, Cunningham SC, Cameron JL, et al. Cholangiocarcinoma: Thirty-one-year experience with 564 patients at a single institution. Ann Surg 2007;245:755-2.

37. Silva MA, Tekin K, Aytekin F, Bramhall SR, Buckels JA, Mirza DF. Surgery for hilar cholangiocarcinoma: A 10 year experience of a tertiary referral centre in the UK. Eur J Surg Oncol 2005;31:533-9.

38. Pichlmayr R, Weimann A, Klempnauer J, et al. Surgical treatment in proximal bile duct cancer: A single-center experience. Ann Surg 1996;224:628-38.

39. Weber SM, Jarnagin WR, Klimstra D, DeMatteo RP, Fong Y, Blumgart LH. Intrahepatic cholangiocarcinoma: Resectability, recurrence pattern, and outcomes. J Am Coll Surg 2001;193:384-91.

40. Jarnagin WR, Fong Y, DeMatteo RP, et al. Staging, resectability, and outcome in 225 patients with hilar cholangiocarcinoma. Ann Surg 2001;234:507-17.

41. Nakeeb A, Pitt HA. Radiation therapy, chemotherapy and chemoradiation in hilar cholangiocarcinoma. HPB (Oxford) 2005; 7:278-82.

42. Dingle BH, Rumble RB, Brouwers MC. Cancer Care Ontario's Program in Evidence-Based Care's Gastrointestinal Cancer Disease Site Group. The role of gemcitabine in the treatment of cholangiocarcinoma and gallbladder cancer: A systematic review. Can J Gastroenterol 2005;19:711-6.

43. Ghali P, Marotta PJ, Yoshida EM, et al. Liver transplantation for incidental cholangiocarcinoma: Analysis of the Canadian experience. Liver Transpl 2005;11:1412-6.

44. Goss JA, Shackleton CR, Farmer DG, et al. Orthotopic liver transplantation for primary sclerosing cholangitis. A 12-year single-center experience. Ann Surg 1997;225:472-83.

45. Becker NS, Rodriguez JA, Barshes NR, O’Mahony CA, Goss JA, Aloia TA. Outcomes analysis for 280 patients with cholangiocarcinoma treated with liver transplantation over an 18-year period. J Gastrointest Surg 2008;12:117-22.

46. Iwatsuki S, Todo S, Marsh JW, et al. Treatment of hilar cholangiocarcinoma (Klatskin tumors) with hepatic resection or transplantation. J Am Coll Surg 1998;187:358-64.

47. Pichlmayr R, Lamesch P, Weimann A, Tusch G, Ringe B. Surgical treatment of cholangiocellular carcinoma. World J Surg 1995;19:83-8.

48. Casavilla FA, Marsh JW, Iwatsuki S, et al. Hepatic resection and transplantation for peripheral cholangiocarcinoma. J Am Coll Surg 1997; 185:429-36.

49. Shimoda M, Farmer DG, Colquhoun SD, et al. Liver transplantation for cholangiocellular carcinoma: Analysis of a single-center experience and review of the literature. Liver Transpl 2001;7:1023-33.

50. Meyer CG, Penn I, James L. Liver transplantation for cholangiocarcinoma: Results in 207 patients. Transplantation 2000;69:1633-7.

51. Robles R, Figueras J, Turrión VS. Spanish experience in liver transplantation for hilar and peripheral cholangiocarcinoma. Ann Surg 2004;239:265-71.

52. Sudan D, DeRoover A, ChinnaKotla S, et al. Radiochemotherapy and transplantation allow long-term survival for non-metastatic hilar cholangiocarcinoma. Am J Transplantation 2002;2:774-9.

53. Rea DJ, Heimbach JK, Rosen CB, et al. Liver transplantation with neoadjuvant chemoradiation is more effective than resection for hilar cholangiocarcinoma. Ann Surg 2005;242:451-61.

54. Yang L, Yan L. Current status of intrahepatic cholangiocarcinoma. World J Gastroenterol 2008;14:6289-97.

55. Sotiropoulos GC, Kaiser GM, Lang H, et al. Liver transplantation as a primary indication for intrahepatic cholangiocarcinoma: A single-center experience. Transplant Proc 2008;40:3194-5.

56. Heimbach JK, Gores GJ, Haddock MG, et al. Predictors of disease recurrence following neoadjuvant chemoradiotherapy and liver transplantation for unresectable perihilar cholangiocarcinoma. Transplantation 2006;82:1703-7.

57. Neuhaus P, Jonas S, Settmacher U, et al. Surgical management of proximal bile duct cancer: Extended right lobe resection increases resectability and radicality. Langenbecks Arch Surg 2003;388:194-200. 




The Scientific World Journal
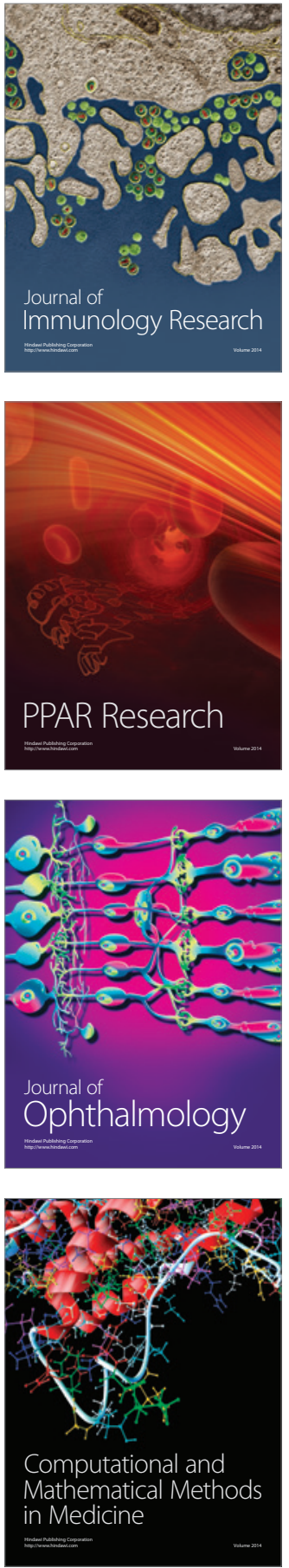

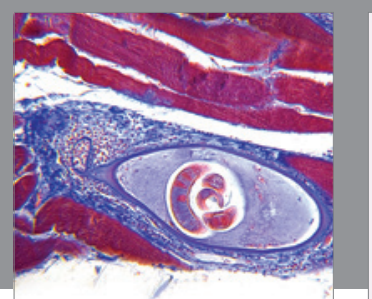

Gastroenterology Research and Practice



\section{Hindawi}

Submit your manuscripts at

http://www.hindawi.com
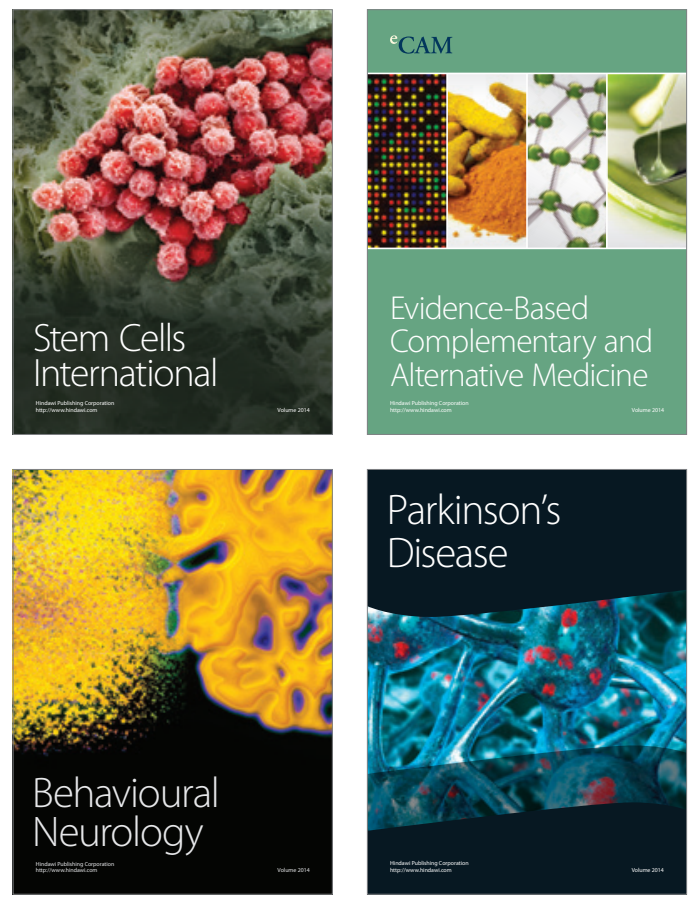
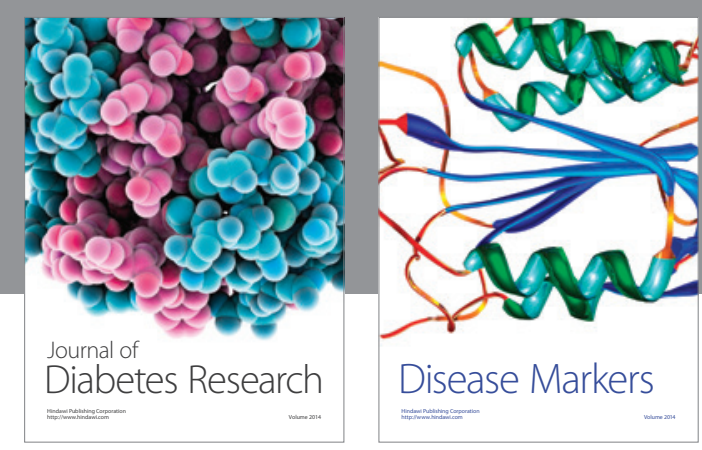

Disease Markers
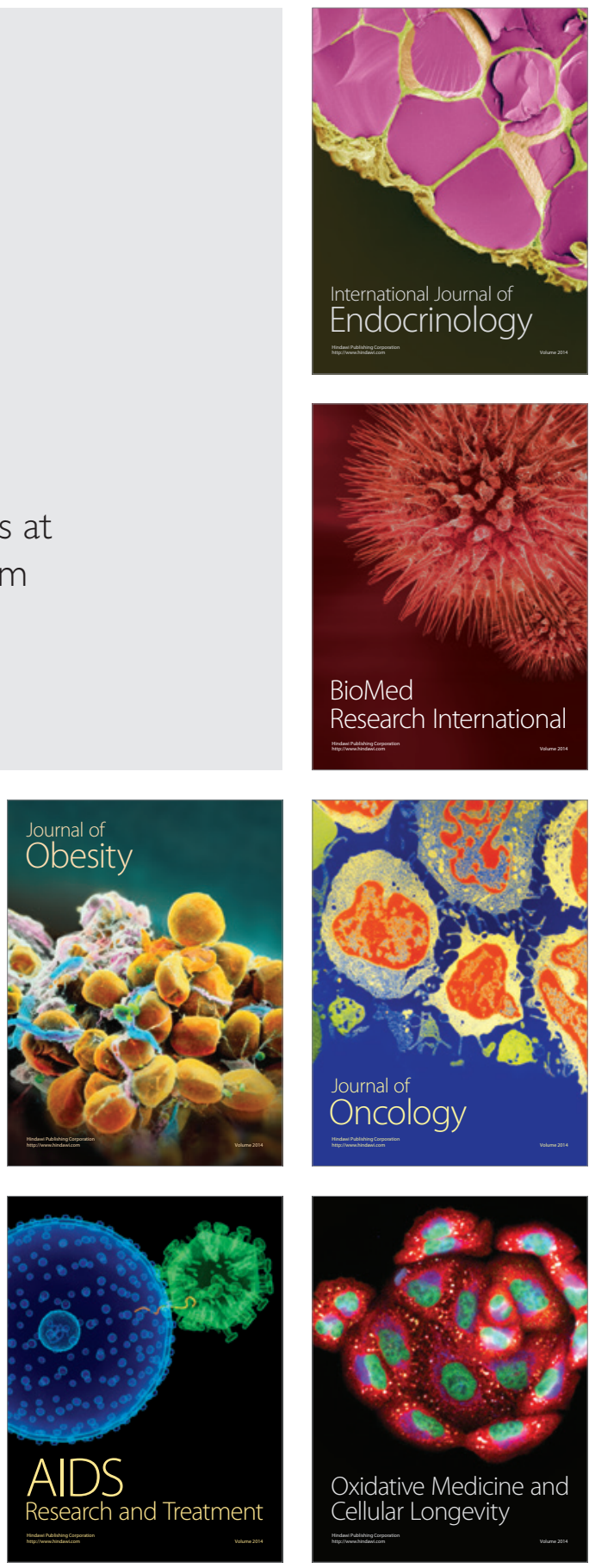